\title{
Comparing the validity of an online Ishihara colour vision test to the traditional Ishihara handbook in a South African university population
}

\begin{tabular}{|c|c|}
\hline $\begin{array}{l}\text { Authors: } \\
\text { Diane van Sta } \\
\text { Fatima Noor I } \\
\text { Sershni Gove } \\
\text { Lunga Lengisi } \\
\text { Benita Singh } \\
\text { Osman Abool }\end{array}$ & $\begin{array}{l}\operatorname{den}^{1} \text { (1) } \\
\text { Uahomed }^{1} \\
\text { Ider }^{1} \\
\text { aker }\end{array}$ \\
\hline \multicolumn{2}{|c|}{$\begin{array}{l}\text { Affiliations: } \\
{ }^{1} \text { Discipline of Optometry, } \\
\text { University of KwaZulu-Natal, } \\
\text { South Africa }\end{array}$} \\
\hline \multicolumn{2}{|c|}{$\begin{array}{l}\text { Corresponding author: } \\
\text { Diane van Staden, } \\
\text { wallaced@ukzn.ac.za }\end{array}$} \\
\hline $\begin{array}{l}\text { Dates: } \\
\text { Received: } 23 \\
\text { Accepted: } 31 \\
\text { Published: } 21\end{array}$ & $\begin{array}{l}\text { Aug. } 2016 \\
\text { Aug. } 2017 \\
\text { Feb. } 2018\end{array}$ \\
\hline \multicolumn{2}{|c|}{$\begin{array}{l}\text { How to cite this article: } \\
\text { Van Staden D, Noor } \\
\text { Mahomed F, Govender S, } \\
\text { Lengisi L, Singh B, Aboobaker } \\
\text { O. Comparing the validity of } \\
\text { an online Ishihara colour } \\
\text { vision test to the traditional } \\
\text { Ishihara handbook in a South } \\
\text { African university population. } \\
\text { Afr Vision Eye Health. } \\
\text { 2018;77(1), a370. https://doi. } \\
\text { org/10.4102/aveh.v77i1.370 }\end{array}$} \\
\hline \multicolumn{2}{|c|}{$\begin{array}{l}\text { Copyright: } \\
\text { (C) 2018. The Author(s } \\
\text { Licensee: AOSIS. This } \\
\text { is licensed under the } \\
\text { Creative Commons } \\
\text { Attribution License. }\end{array}$} \\
\hline \multicolumn{2}{|l|}{ Read online: } \\
\hline 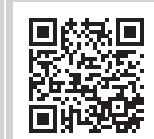 & $\begin{array}{l}\text { Scan this QR } \\
\text { code with your } \\
\text { smart phone or } \\
\text { mobile device } \\
\text { to read online. }\end{array}$ \\
\hline
\end{tabular}

Background: Colour vision tests are becoming increasingly available on online platforms to the ordinary internet user. Limited research has been conducted to establish the validity of these tests for use as screening tools for colour deficiency.

Aim: To compare the validity of an online version of the Ishihara colour vision test (OV-PSI) with the traditional Ishihara handbook (PSI).

Setting: This study was conducted at the University of KwaZulu-Natal's optometry clinic in Durban, South Africa, in 2014.

Methodology: One hundred and twenty participants $(N=120)$, between the ages of 18 and 25 years who visited the University of KwaZulu-Natal's eye clinic between June and August 2014, were recruited to the study. Colour vision testing was administered using the Ishihara 38 plate test and the ColBlindor Ishihara 38 plate colour vision test available online. Both tests were administered on normal sighted university student participants under standardised conditions, and responses were captured on Ishihara recording sheets. Data were analysed using the Statistical Package of Social Science (SPSS) version 21.

Results: Of the 120 participants, $47.5 \%$ were men and $52.5 \%$ were women with a mean age of $20.64 \pm 2.09$ years. Results demonstrated that $5.3 \%$ of men $(N=3)$ were colour deficient, resulting in a prevalence of colour deficiency for the sampled population of $2.5 \%$. Results of the two testing methods were compared, revealing sensitivities and specificities for both tests of $100 \%$. However, while the online test correctly discriminated colour deficient participants from colour normal participants, it was unable to correctly identify the severity or type of deficiency.

Conclusion: The online version of the Ishihara test used in this study proved a valid screening tool for colour vision deficiency. It presents the opportunity for self-screening via convenient online platforms. However, if colour deficiency is detected using this online tool, it is recommended that further clinical investigation be undertaken for a more accurate diagnosis of the extent of colour vision deficiency.

\section{Introduction}

Colour vision testing is the assessment of chromatic discrimination ability and the diagnosis of any perceptual deficiency. ${ }^{1}$ It forms part of the functional assessment of the visual system conducted by optometrists during routine eye examinations. Technological advances have resulted in digital versions of commonly used colour vision tests, such as the Ishihara test for colour vision, now becoming accessible to the general public via online platforms.

Colour perception is made possible by cone photoreceptor cells found in the retina. ${ }^{2}$ There are three types of cone photoreceptors, each with a different spectral sensitivity and containing a different photo pigment. These correspond to the three primary colours, namely, red ([longwavelength] $558 \mathrm{~nm}$ maximum absorption), green ([medium-wavelength] $531 \mathrm{~nm}$ maximum absorption) and blue ([short-wavelength] $419 \mathrm{~nm}$ maximum absorption), resulting in the term trichromacy. ${ }^{3}$ Additive mixtures of these colours then result in all spectral hues. ${ }^{4}$ Colour vision is, therefore, derived from the interactions of numerous wavelengths of light energy, the absorption of light by photosensitive pigments in the cone cells of the retina and their subsequent neural interpretation within the visual system. Not all people possess trichromacy, however, with some being partially colour deficient, confusing colours that trichromats discern easily, or completely 'colour blind' (monochromatic), perceiving no colour at all. Certain pathological conditions such 
as cataract and glaucoma may present with acquired colour vision deficiencies, ${ }^{5}$ warranting further examination and routine monitoring.

Red-green colour deficiency is the most common form of colour deficiency and is a generic term for protanopia (red-deficiency), protanomaly (red-weakness), deuteranopia (green-deficiency) and deuteranomaly (green-weakness). ${ }^{5}$ More than $99 \%$ of all affected people have red-green colour deficiency, with a greater prevalence in men. ${ }^{6,7}$ Colour deficiency may be caused by ocular disease, trauma or medication, ${ }^{3}$ as well as normal physiological processes such as ageing. People who are colour deficient may experience challenges with activities of daily living which require colour discrimination. Furthermore, specific occupational classes such as pilots and electricians require accurate colour perception to be able to safely perform their duties.

The Ishihara test is commonly used to diagnose colour deficiency. The test consists of pseudo-isochromatic plates and has been found to be a reliable screening method for colour deficiency. ${ }^{6}$ Pseudo-isochromatic plates consist of a figure or pattern composed of coloured dots of varying sizes embedded in a background of differently coloured dots. Colour differences among the circles demarcate the foreground design (digits, simple geometric forms or curved lines) so that for a normal trichromat, the design stands out from its background. ${ }^{1}$ When administering the test, observers are required to identify the pattern or figure embedded in the plate. Several online versions of the Ishihara colour vision test are now available, suggesting widespread implications for self-screening by the general public. With technology now integrated into daily life, a reliable online colour vision test may be a convenient and cost-effective alternative to screening for colour vision defects.

Birch $^{6}$ determined the efficiency of the Ishihara test to identify red-green colour deficiencies using 401 participants. Combined sensitivity of the transformation and vanishing plates of the 38 plate Edition of the Ishihara confirmed that it is an efficient screening method for protan and deutan colour deficiency. Several studies have compared the Ishihara Pseudo-isochromatic plate test to modified electronic versions. Gündogan et al. ${ }^{8}$ compared the efficiency of projected colour slides in detecting colour deficiency, compared with the classic method of the Ishihara Pseudo-isochromatic plates. The authors concluded that using projected slides was an effective and timesaving method for detecting colour deficiency. Ganley et al. ${ }^{9}$ conducted a study in which a similar method of projected colour slides were used as a method for mass screening of red-green colour deficient individuals. The sensitivity of the screening system was $100 \%$, with authors suggesting that projected colour slides are potentially useful as a screening method to detect individuals with red-green colour deficiencies.

Hoffmann and Menozzi ${ }^{10}$ compared the traditional Ishihara test to a computer-based screening system using 10 colour normal and 10 colour deficient subjects. Results indicated that despite the differences between the spectral emission of the monitor and the reflected daylight with conventional Ishihara plates, the computer-based method correctly discriminated subjects with colour deficiencies from those without such deficiencies. However, Rodriguez-Carmona et al. ${ }^{11}$ noted that approximately $20 \%$ of normal trichromats fail the test, suggesting limitations in its application.

The aim of this study was, therefore, to compare the validity of an online version of the Ishihara colour vision test (http:/ / www.color-blindness.com/ishihara-38-plates-cvdtest/) to the traditional Ishihara 38 plate handbook. In the context of this study, validity was considered to be the extent to which the online test was able to distinguish colour normal patients from those with colour deficiency. To date, no research has been conducted to test the validity of this online Ishihara test as an alternative screening tool to the traditional handbook typically administered in-office by professionals. This study was, therefore, conducted to explore the potential for use of online colour vision tests as a self-screening tool for colour vision deficiency by nonoptometric persons.

\section{Methods}

Ethical clearance was obtained from the Biomedical Research and Ethics Committee at the University of KwaZulu-Natal (UKZN). A comparative study was conducted using convenient, non-probability sampling of student participants from the UKZN Westville campus in Durban, South Africa. One hundred and twenty participants $(N=120)$, between the ages of 18 and 25 years who visited the eye clinic, were recruited to the study following informed consent. Visual acuities at distance and near were assessed, and ophthalmoscopy was performed to rule out the presence of ocular pathology. Participants who presented with ocular pathology or visual acuities worse than 6/6 (corrected) were excluded from participating in the study. Participants who required spectacle or contact lens correction wore these during administration of the tests.

The testing was administered under standardised conditions. Room illumination was measured to be 410 lux with the computer monitor for the online test set against recommended display settings. A standardised test distance of $75 \mathrm{~cm}$ was maintained for both the online and handbook testing methods in keeping with test distances for other pseudoisochromatic plate designs. ${ }^{12}$

The two tests were conducted monocularly in succession, beginning with the right eye for uniformity and then repeated on the left eye after an interval of $30 \mathrm{~min}$. The handbook and online versions of the Ishihara were administered in a randomised order. The 38-plate version of the handbook was used to screen for colour vision deficiency, which includes four plate designs, namely, transformation, vanishing, hidden digit and diagnostic plates. To begin the 
testing, the demonstration plate (plate 1) designed to be seen by all individuals was used to demonstrate to participants what may be seen. This was followed by the transformation plates (2-9), where the intended image is seen by normal colour vision individuals, while a colour vision defective person sees a different image. The second set, vanishing plates (10-17), enables colour normals to see figures which those with colour deficiencies are unable to discern. The hidden digit plates (18-21) include images not seen by people with normal colour vision, but which can be seen by colour defective individuals. Finally, the diagnostic plates (22-25) are designed to be seen by both the colour normal and colour defective individuals, with colour defective individuals seeing only one digit, or seeing one digit more easily than another.

The online version of the Ishihara that was used was the ColBlindor test (http://www.color-deficiency.com), which is basically meant as an exact replica of the 38-plate handbook. For the online test, participants would be seated in front of a laptop computer at the required test distance, with the researcher directing transition of the slides in sequential order on the monitor. Participants were required to identify the image seen in the plate, and their verbal responses were recorded by the researcher on a standard Ishihara recording sheet.

The online version interprets its results by differentiating between colour deficient and colour normal persons, indicating the severity of the colour deficiency (weak, moderate or severe). However, on its own, it is unable to classify the type of colour vision deficiency, for example, protan or deutan. The pass or fail criterion followed was standard for the 38 plate Ishihara test, where nine errors or more classifies a participant as having a red-green colour deficiency and failing the test. Based on these results, subjects were grouped as being either colour normal or colour deficient.

Data were captured using Microsoft Excel and analysed using the Statistical Package of Social Science (SPSS version 21). Fischer's exact test was used to analyse the data, and a $p$-value $<0.05$ was considered statistically significant. Sensitivity and specificity of the online version of the Ishihara colour vision test were also calculated.

\section{Results}

One hundred and twenty participants $(N=120)$ were assessed, $47.5 \%$ of whom were men and $52.5 \%$ were women, aged between 18 and 25 years (mean age $=20.64 \pm 2.09$ years). Most of the participants were Africans (47\%), followed by Indians (46\%), Caucasians $(4 \%)$ and mixed race $(3 \%)$. The results showed that 3 of the 57 men $(5.3 \%)$ were colour deficient and none of the women, with an overall prevalence of colour deficiency being $2.5 \%(3 / 120)$ for the sampled population (Table 1).

Sensitivity in this study was defined as the ability of the screening test to detect all individuals who had red-green colour vision defects. Specificity was defined as the ability to detect all individuals who do not have red-green colour vision defects. The sensitivity and the specificity of the online version were both found to be $100 \%$ (Table 2), and a $p$-value of $<0.05$ was obtained. The handbook version was used for comparison.

Men who failed the screening had varying responses on the online version when compared to the handbook, although an overall fail was noted (Figure 1). Participants with normal colour vision, however, responded to the online version in a similar manner as they did for the traditional handbook. The least amount of differences between handbook and online version where noted on plates 7, 10-17 and 22-25. Plates with the most significant difference between handbook and online version were plates 18-21, which are the hidden digit plates. These variations could possibly be because of the spectral quality of the light source, illumination of the plates or the impact of the screen resolution on perception of colour patterns.

The online version, however, successfully identified a colour vision deficient person, although it did not accurately detect the extent of the deficiency (strong, moderate or weak). This may be because of the fact that an identical depiction of the slides of the handbook was not possible because of the scanned nature of the online slides which possibly contributes to colour variations. All three colour deficient participants passed the hidden digit plates (plates 18-21) on the online versions, decreasing the actual number of plates failed. There is, therefore, a similarity between results

TABLE 1: Comparison between colour defective and colour normal individuals in the study using the online version of the Ishihara test.

\begin{tabular}{|c|c|c|c|c|c|}
\hline \multirow[t]{2}{*}{ Gender } & \multicolumn{2}{|c|}{ Colour normal } & \multicolumn{2}{|c|}{ Colour deficient } & \multirow[t]{2}{*}{ Total } \\
\hline & Number & $\%$ & Number & $\%$ & \\
\hline Males & 54 & 45.0 & 3 & 5.3 & 57 \\
\hline Females & 63 & 52.5 & 0 & 0.0 & 63 \\
\hline Total & 117 & 97.5 & 3 & 2.5 & 120 \\
\hline
\end{tabular}

TABLE 2: Sensitivity and specificity of the online and traditional versions of the Ishihara colour vision test as found in this research.

\begin{tabular}{|c|c|c|c|c|}
\hline \multirow[t]{2}{*}{ Colour vision classification } & \multirow[t]{2}{*}{ Handbook: Number } & \multicolumn{3}{|c|}{ Online version } \\
\hline & & Number & Sensitivity (\%) (true colour deficient) & Specificity (\%) (true colour normal) \\
\hline Normal colour vision & 117 & 117 & 0 & 100 \\
\hline Colour vision deficient & 3 & 3 & 100 & 0 \\
\hline Total & 120 & 120 & - & - \\
\hline
\end{tabular}




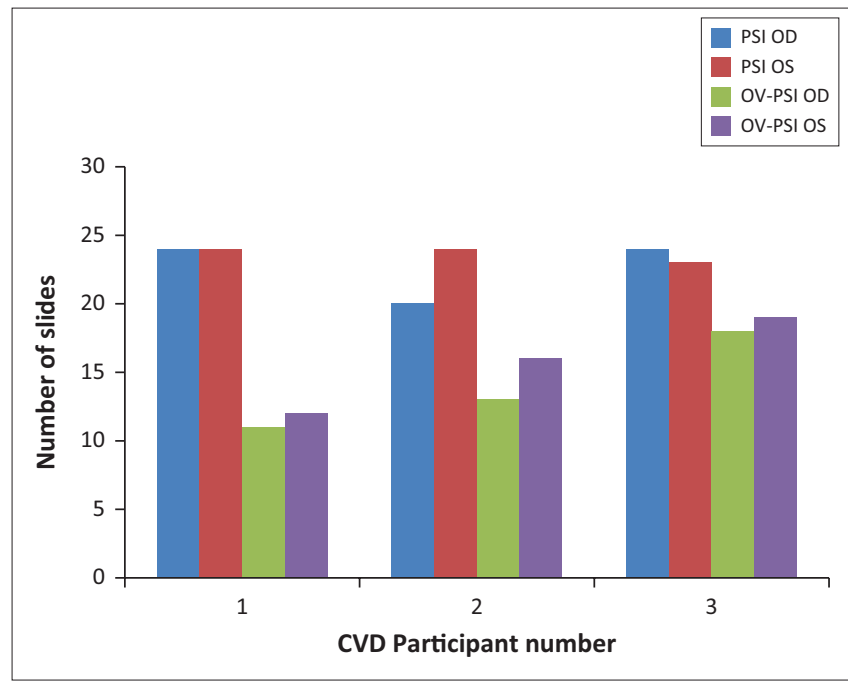

CVD, Colour Vision Deficiency; PSI OD, Traditional Ishihara Right Eye; PSI OS, Traditional Ishihara Left Eye; OV-PSI OD, Online Version of Ishihara Right Eye; OV-PSI OS, Online version of Ishihara Left Eye.

FIGURE 1: A comparison of the number of failed plates between the Ishihara traditional handbook and the online version by the three colour deficient participants in the study, with results for each eye.

obtained with the online version of the Ishihara colour vision test and the traditional handbook method ( $p$-value $\leq 0.05$ ), and thus the results would be considered clinically significant.

\section{Discussion}

The results of this research show that the online version of the Ishihara Pseudo-isochromatic Colour Vision Test is a possible alternative to screening for colour deficiency. However, the test has limitations in that it was not able to accurately detect the severity of the deficiency. The fact that all colour deficient and colour normal individuals who participated in the study were correctly classified suggests that this test can be used for screening purposes by untrained persons. Where positively identified as having colour deficiency, this would warrant more thorough in-office assessment by an appropriately educated professional.

In keeping with Hoffman and Menozzi, ${ }^{10}$ this study confirmed that despite the differences between the spectral emission of the monitor and the reflected artificial light with the Ishihara plates, the computer-based method was able to discriminate between people with and without colour deficiencies. The sensitivity and specificity of the online version of the Ishihara correlates with results by Gündogan et al. ${ }^{8}$ and Ganley et al. ${ }^{9}$ Although a limitation of this study is the relatively small sample size, the results of the study provide useful information for optometric practitioners and the general public on the use of online methods for screening colour deficiency. It is recommended that future research should include a larger, more representative sample, as well as consider the use of different types of monitors and the impact of lighting and screen resolution on online testing results.

\section{Conclusion}

The Colblinder online Ishihara 38 plate test for colour vision deficiency is a valid screening test for colour vision deficiency which has implications for self-screening given its accessibility to the general public. The test correctly identifies the presence of a colour vision deficiency, although it cannot indicate the severity or the type of deficiency present. Online screening tools for colour vision deficiency may, therefore, provide a convenient, self-screening alternative to in-office assessments. However, any person identified as colour deficient by this online screening tool will require further assessment to determine the type and extent of deficiency present.

\section{Acknowledgements Competing interests}

The authors declare that they have no financial or personal relationships which may have inappropriately influenced them in writing this article.

\section{Authors' contributions}

D.v.S. supervised the undergraduate research project conducted by honours students at the University of KwaZulu-Natal (all remaining co-authors). All students were involved in conceptualising, designing and undertaking the research and preparing the draft manuscript. The final version of the manuscript was prepared by D.v.S.

\section{References}

1. Paramei G, Bimler D. Colour vision testing. In: Encylopedia of color science and technology. New York: Springer Science and Bisness Media, 2015; p. 1-7.

2. Encyclopaedia Britannica. Structure and function of photoreceptors [homepage on the Internet]. [cited 2017 Aug 28]. Available from: https://www.britannica. com/science/photoreception/Structure-and-function-of-photoreceptors

3. Sehlapelo R, Oduntan A. Effect of optical defocus on colour perception. S Afr Optom. 2007;66(2):77-81. https://doi.org/10.4102/aveh.v66i2.229

4. Rosenfield M, Logan N. Optometry: Science, techniques and clinical management. 2nd ed. London: Elsevier Ltd; 2009.

5. Hasron N, Rubin A. Defects of colour vision: A review of congenital and acquired colours vision deficiency. Afr Vision Eye Health. 2016;75(1):1-6.

6. Birch J. Worldwide prevalence of red-green color deficiency. J Opt Soc Am A Opt Image Sci Vis. 2012:29(3):313-320. https://doi.org/10.1364/JOSAA.29.000313

7. Gordon N. Colour deficiency. Public Health. 1998;112(2):81-84. https://doi. org/10.1016/S0033-3506(98)00590-3

8. Gündogan NU, Durmazlar N, Gümüş K, et al. Projected color slides as a method for mass screening test for color vision deficiency (a preliminary study). Int J Neurosci. 2005;115(8):1105-1117. https://doi.org/10.1080/00207450590914365

9. Ganley JP, Lian MC. Projected color slides as a method for mass screening of red-green color deficient individuals. Ophthalmic Epidemiol. 1997;4(4):213-221. https://doi.org/10.3109/09286589709059195

10. Hoffmann A, Menozzi M. Computer-based determination of red/green colour vision defects. Biomed Eng. 1998;43(5):124-132. https://doi.org/10.1515/ bmte.1998.43.5.124

11. Rodriguez-Carmona M, O'Neill-Biba M, Barbur JL. Assessing the severity of colour vision loss with implications for aviation and other occupational environments. Aviat Space Environ Med. 2012;83(1):19-29. https://doi. org/10.3357/ASEM.3111.2012

12. National Research Council. Procedures for colour vision tests [homepage on the Internet]. Report of Working Group 41. Washington, DC: National Academies Press; 1981 [cited 2017 Aug 29]. Available from: https://www.ncbi.nlm.nih.gov/ books/NBK217823/ 